\section{Congenital horizontal gaze palsy and kyphoscoliosis}

SIR,

In the August 1979 issue of your Journal (JMG, 16, 314-6) there was an interesting paper by Drs Elizabeth Riley and Michael Swift entitled, 'Congenital horizontal gaze palsy and kyphoscoliosis in two brothers'.

Because the authors stated that familial congenital horizontal gaze palsy in association with scoliosis had not been described previously, I wish to inform you that the above syndrome was described in detail by me for first time in 1970 in three children of a Greek family. ${ }^{1}$ In a second paper published in $1974,{ }^{2}$ I described with P Kontoyannis five children of two Greek families presenting with congenital absence of lateral eye movement and scoliosis.

A more detailed study of the above syndrome, based on ten personal cases, is set out in research work that we are at present undertaking. It must also be stated that the same syndrome has been described by Tezuka ${ }^{3}$ and Yamada et $a^{4}$ in four Japanese children.

E K DRetakis 37 Ipsilantou Street, Athens 140, Greece

References

1 Dretakis EK. Familial idiopathic scoliosis associated with encephalopathy in three children of the same family. Acta Orthop Hell 1970;22:51-5.

2 Dretakis EK, Kontoyannis PN. Congenital scoliosis associated with encephalopathy in five children of two families. J Bone Joint Surg (Am) 1974;56:1747-50.

8 Tezuka A. Development of scoliosis in cases with congenital organic abnormalities of the brain-stem. Tokushima J Exp Med 1971 ;18:49-62.

4 Yamada K, Yamamoto H, Tamura T, Tezuka A. Development of scoliosis under neurological basis, particularly in relation with brain-stem abnormalities. J Bone Joint Surg (Am) 1974;56:1764-5.

This letter was shown to Drs Riley and Swift who reply as follows:

SIR,

We are grateful to Dr Dretakis for pointing out the previous reports of patients with scoliosis and oculomotor abnormalities.

The affected subjects described by Dretakis and Kontoyannis ${ }^{2}$ and Tezuka $^{3}$ do present similar clinical features to those we described in two brothers with kyphoscoliosis and congenital horizontal gaze palsy. Unlike our patients, however, these affected subjects had either retained the $\frac{\bar{C}}{\widetilde{\alpha}}$ ability to converge or adduct the eyes or had, in addition to a horizontal gaze palsy, limitation of so vertical gaze. The association of kyphoscoliosis and $\vec{\circ}$ ocular gaze abnormalities in sibs of different sex andthe presence of parental consanguinity in our family $\vec{\omega}$ and the three cases reported by Tezuka ${ }^{3}$ is further support for autosomal recessive inheritance.

Elizabeth Riley aNd Michael Swift $\vec{v}$ Division of Medical Genetics, Department of Medicine, Biological Sciences Research Center, N University of North Carolina, Chapel Hill, North Carolina 27514, USA을

\section{Classification of inherited brachydactylies}

SIR,

In the February 1979 issue of the Journal of Medical $\vec{\circ}$ Genetics, Dr Naomi Fitch presented a classification ${ }^{\infty}$ and identification of inherited brachydactylies. ${ }^{1}$ Our paper on brachydactyly ${ }^{2}$ has been grouped by $\mathrm{Dr}^{0}$ Fitch under apical dystrophy, Bell type B (pp 37-8), which is characterised by the absence of the terminal portions of fingers 2 to 5 along with the usual $\frac{0}{0}$ absence of nails. The feet are also reported to be mildly involved. But if one compares our case witho this type, there are many obvious differences. The major differences are two. (1) One palm was brachydactylous while the other was normal and both hands had nails (smaller in the brachydactylous $\bar{\exists}$ palm). (2) Both feet were severely involved with no $-{ }_{-}^{\circ}$ toes at all. All the phalanges were buried within the 3 distal border of the blunt foot and there were noo appreciable digital projections. Strictly speaking, our 3 proband is a new combination of brachydactyly with associated malformations. Nevertheless, Dr? Fitch's comprehensive article deserves full appreci- $-\frac{7}{0}$ ation.

H K Goswami AND B D Chaurasia ô Genetics Laboratory, School of Biological Sciences, N Bhopal University, Bhopal, MP, andN Department of Anatomy, ${ }_{\sigma}$ GR Medical College Gwalior, MP, India

References

1 Fitch N. Classification and identification of inherited brachydactylies. J Med Genet 1979;16:36-44.

2 Goswami HK, Chaurasia BD. Gene interaction in brachydactyly. Jpn J Hum Genet 1974;18:405-10. 